Arq. Bras. Med. Vet. Zootec., v.56, n.6, p.782-787, 2004

\title{
Comparação entre os métodos de referência e a análise eletrônica na determinação da composição do leite bovino
}

[Comparison between standard methods and electronic analyses for measurement of the bovine milk composition]

\author{
T.M.L. Silveira ${ }^{1}$, L.M. Fonseca ${ }^{2}$, S.V. Cançado ${ }^{2}$, V. Ferraz ${ }^{3}$ \\ ${ }^{1}$ Mestre em Medicina Veterinária \\ ${ }^{2}$ Departamento de Tecnologia e Inspeção de Produtos de Origem Animal \\ Escola de Veterinária da UFMG \\ Caixa Postal 567 \\ 30123-970 - Belo Horizonte, MG \\ ${ }^{3}$ Departamento de Química da UFMG
}

\begin{abstract}
RESUMO
Avaliou-se a metodologia de determinação da composição do leite por meio de analisador de infravermelho, utilizando-se 48 amostras individuais de leite de vacas da raça Holandesa e cinco amostras de leite de conjunto. A média dos resultados para gordura, proteína, lactose e sólidos totais das amostras individuais foram, respectivamente, $3,8 \%, 3,3 \%, 4,6 \%$ e $12,4 \%$, usando-se metodologia de referência e $3,8 \%, 3,3 \%, 4,5 \%$ e $12,4 \%$, usando-se equipamento eletrônico. Para amostras de tanque, as médias foram $3,9 \%$ e $4,0 \%$ para gordura, $3,2 \%$ e $3,2 \%$ para proteína, $4,7 \%$ e $4,6 \%$ para lactose e $12,6 \%$ e $12,6 \%$ para sólidos totais, respectivamente, para análises feitas por métodos de referência e por analisador de infravermelho. Não houve diferença $(\mathrm{P}>0,05)$ entre os valores das duas análises. Foi avaliada a qualidade das amostras-padrão canadense e americano, determinando-se os teores de gordura, proteína, lactose e sólidos totais por métodos de referência. Os resultados foram comparados com os valores declarados no laudo de análise das amostras, emitidos pelo laboratório fornecedor.
\end{abstract}

Palavras-chave: composição do leite, analisador de infravermelho, amostra padrão, qualidade do leite

\begin{abstract}
In order to evaluate an electronic method for determination of milk composition based on infrared determination, 48 raw milk samples from Holstein cows and five bulk tank samples were analyzed for fat, protein, lactose and total solids contents. Results for fat, protein, lactose, and total solids contents for raw milk samples were, respectively, 3.8\%, 3.3\%, 4.6\% and $12.4 \%$ using the standard methods, and $3.8 \%, 3.3 \%, 4.5 \%$, and $12.4 \%$, using electronic equipment. For the bulk tank samples results for fat, protein, lactose and total solids contents were, respectively, 3.9\%, 3.2\%, 4.7\%, and $12.6 \%$ using the standard methods, and $4.0 \%, 3.2 \%, 4.6 \%$, and $12.6 \%$ using electronic equipment. No differences between values obtained from both analytical methods were observed $(P>0.05)$. The quality of the American and Canadian standard samples was evaluated by determination of fat, protein, lactose and total solids contents, using the reference methods to compare the composition of the standard samples to the results of analyses issued by the supplier laboratory.
\end{abstract}

Keywords: milk composition, infrared, reference samples, milk quality

Recebido para publicação em 3 de dezembro de 2003

Recebido para publicação, após modificações, em 1 de outubro de 2004

*Autor para correspondência

E-mail: labufmg@vet.ufmg.br 


\section{INTRODUÇÃO}

A granelização do leite e a implantação de programas de pagamento do leite pela qualidade demandaram a introdução de técnicas rápidas e modernas de análises de leite e resultaram na instalação da Rede Brasileira de Laboratórios para o Controle da Qualidade do Leite (Ministério da Agricultura, Pecuária e Abastecimento). As metodologias de análises de referência são laboriosas e exigem tempo para serem executadas, não sendo mais recomendadas para o acompanhamento da qualidade do leite de rebanhos com grande número de animais. A utilização de equipamentos eletrônicos para análises rápidas tem sido uma alternativa para facilitar o controle leiteiro e a avaliação da qualidade do leite.

Para a determinação dos componentes do leite (gordura, proteína, lactose e sólidos totais) são utilizados os analisadores rápidos de infravermelho, método de análise prático e econômico, pela possibilidade de se analisar um grande número de amostras (Barbano e Clark, 1989).

O princípio fundamental de todos os analisadores de infravermelho baseia-se na capacidade de absorção de radiação, em diferentes comprimentos de ondas, dos grupos químicos específicos de alguns componentes do leite como gordura, proteína e lactose (Biggs, 1987). De acordo com a lei de Beer-Lambert, a porcentagem de cada constituinte é relacionada com a quantidade de energia absorvida. Ela estabelece que a absorvância da luz por uma solução, numa determinada espessura, é diretamente proporcional à concentração de um componente (Guillou et al., 1976; Biggs, 1987).

Os objetivos do trabalho foram comparar métodos de análise de composição do leite e avaliar a qualidade das amostras-padrão importadas, de origens americana e canadense, utilizadas na calibração dos equipamentos eletrônicos de análises rápidas.

\section{MATERIAL E MÉTODOS}

As análises de gordura, proteína e sólidos totais do leite, feitas por métodos de referência, foram realizadas no Laboratório Regional de Apoio
Animal-LARA/MG, localizado em Pedro Leopoldo, Minas Gerais, e as análises de lactose no laboratório de cromatografia do Departamento de Química da UFMG. As análises pelo analisador de infravermelho foram feitas no laboratório de controle leiteiro da Associação Paranaense dos Criadores de Rebanho Bovino da Raça Holandesa, localizado em Curitiba, Paraná.

Foram analisadas 48 amostras individuais de leite de vacas da raça Holandesa, de várias idades e diferentes estádios de lactação, escolhidas aleatoriamente em um rebanho e cinco amostras de leite do tanque de resfriamento obtidas no mesmo local. As amostras individuais foram obtidas do leite total da ordenha. Usaramse 24 amostras-padrão para a calibração dos equipamentos eletrônicos, 12 fornecidas pelo Dairy Quality Control Inc. (DQCI Services), credenciado pela Secretaria de Agricultura de Minnesota, Estados Unidos e 12 pelo Dairy Herd Analysis System (DHAS), credenciado pelo governo canadense. Ambos os laboratórios são oficiais e aprovados pela International Dairy Federation (IDF). Para análise das 22 primeiras amostras, o equipamento foi calibrado com os padrões americanos e o restante com os padrões canadenses. Foram feitas duas repetições de cada amostra. $\mathrm{O}$ analisador de infravermelho utilizado para as determinações foi calibrado segundo as instruções contidas no manual de operações do equipamento (Bentley..., 1994).

Após completa homogeneização da amostra, $250 \mathrm{ml}$ de leite foram colhidos e transferidos para um frasco de vidro contendo tabletes do conservante bronopol (2-bromo-2-nitro-1,3propanodiol) na concentração de $8 \mathrm{mg}$ do ingrediente ativo para cada $40 \mathrm{ml}$ da amostra. $\mathrm{O}$ frasco foi homogeneizado por inversão até completa dissolução do comprimido e as amostras permaneceram sob refrigeração a $4^{\circ} \mathrm{C} \pm 1^{\circ} \mathrm{C}$, até o momento das análises, conforme International... (1995).

A partir das amostras usadas nas análises por métodos de referência, foram obtidas subamostras. Elas foram transferidas para um frasco de plástico com capacidade de $80 \mathrm{ml}$ e acondicionadas em recipiente isotérmico contendo gelo reciclável. A entrega no laboratório de destino, em Curitiba/PR, foi, no 


\section{Silveira et al.}

máximo, 12 horas após o despacho na companhia aérea.

Os métodos de referência usados para determinar os componentes gordura, proteína e sólidos totais das amostras de leite e das amostras-padrão foram, respectivamente, Rose Gottlieb, Kjeldahl e gravimétrico (International..., 1987). A lactose foi determinada por cromatografia líquida de alta eficiência (HPLC), método adaptado de Harvey (1988). O HPLC tem sido amplamente utilizado em laboratórios de análise de leite para a padronização do teor de lactose das amostras padrão, usadas na calibração de analisadores de infravermelho. Para a análise eletrônica utilizouse o equipamento Bentley $2000^{1}$.

Os dados foram analisados por meio de estatísticas descritivas e análise de variância depois do teste para homogeneidade de variância proposto por Levene (SPSS, 1996). Os programas estatísticos usados foram o SPSS 9.0 e o Minitab 10.0 para Windows.

\section{RESULTADOS E DISCUSSÃO}

Os resultados de composição das amostraspadrão não foram estatisticamente diferentes dos resultados fornecidos nos laudos emitidos pelos laboratórios fornecedores das amostras-padrão (Tab.1 e 2). As amostras-padrão canadense apresentaram grande variação nos teores de gordura e sólidos totais, o que resultou em valores diferentes de desvio-padrão em relação às amostras-padrão americano. A estatística descritiva é apresentada na Tab. 3.

Não foi verificada diferença significativa $(\mathrm{P}>0,05)$ entre os dois métodos quanto aos teores de gordura, proteína, lactose e sólidos totais das amostras individuais e do tanque de resfriamento (Tab. 4 e 5).

As correlações (r) entre os dois métodos de análises foram positivas e altas: para gordura, $\mathrm{r}=0,99$; para proteína, $\mathrm{r}=0,98$; para lactose, $\mathrm{r}=0,97$ e para sólidos totais, $\mathrm{r}=0,99$. Pelo teste Levene constatou-se homogeneidade de variância para os dois grupos $(\mathrm{P}>0,05)$, independente da origem da amostra-padrão.

\footnotetext{
${ }^{1}$ Bentley Instruments Incorporated - Minesota, USA.
}

Quando se fez a calibração com amostras-padrão de origem americana seguida de calibração com amostras-padrão de origem canadense, houve dificuldade de ajuste do equipamento para calibração da lactose e sólidos totais. No Brasil, alguns laboratórios que trabalham com analisadores de infravermelho também relataram essa dificuldade. Contudo, não foi observada diferença $(\mathrm{P}>0,05)$ entre os valores obtidos nos dois métodos de análises.

Os resultados dos teores de gordura e proteína seguem distribuição normal. O valor de gordura foi semelhante ao observado por Harding (1995), $3,9 \%$, e superior ao citado por Nickerson (1995), $3,6 \%$, e Picinin (2003), 3,6\%.

A variação encontrada nos resultados obtidos para a gordura nas amostras individuais de leite foi também observada por alguns pesquisadores. Jensen (2002) afirmou ser a gordura o componente de maior variabilidade no leite. Auldist et al. (1998) verificaram que o estádio de lactação influencia o teor de gordura do leite. Assim, a variação observada pode estar relacionada a esse efeito, visto que as amostras foram colhidas em vacas em diferentes estádios de lactação.

Segundo a International...(1996) amostras de leite com concentração de gordura maior que $7 \%$ interferem na performance do equipamento, podendo ocorrer desvio da curva-padrão de calibração. Este fator foi controlado, tendo havido monitoramento constante da colheita das amostras.

Os valores da proteína do leite das amostras individuais estão dentro da faixa de concentração citada por Swaisgood (1992), 3,0\% a 3,5\%, por Harding (1995), 3,2\% e por Brito et al. (2003), $3,1 \%$ a $3,4 \%$. Os valores da proteína do leite de conjunto situam-se acima das porcentagens citadas por Dürr (2003), 2,9\% a 3,2\%. Essas diferenças podem estar relacionadas a fatores nutricionais e de raça.

Os valores da lactose do leite das amostras individuais foram inferiores aos observados por Nickerson (1995), 4,6\%, e por Goff e Hill (1993), 4,8\% a 5,2\%. Os teores de lactose nas amostras de leite não seguem distribuição normal. 
Tabela 1. Composição físico-química das amostras-padrão americano usadas na calibração do equipamento Bentley 2000 de acordo com os laudos fornecidos pelo laboratório Dairy Quality Control Inc. (DQCI Services)

\begin{tabular}{|c|c|c|c|c|c|c|c|}
\hline \multirow{2}{*}{ Amostra } & \multicolumn{2}{|c|}{$\begin{array}{l}\text { Teor de gordura } \\
(\mathrm{g} / 100 \mathrm{~g})\end{array}$} & \multicolumn{2}{|c|}{$\begin{array}{c}\text { Teor de proteína } \\
(\mathrm{g} / 100 \mathrm{~g})\end{array}$} & \multicolumn{2}{|c|}{$\begin{array}{c}\text { Teor de lactose } \\
(\mathrm{g} / 100 \mathrm{~g})\end{array}$} & \multirow{2}{*}{$\begin{array}{l}\text { Sólidos totais } \\
(\mathrm{g} / 100 \mathrm{~g})\end{array}$} \\
\hline & Babcock & $\begin{array}{l}\text { Extrato } \\
\text { etéreo }\end{array}$ & $\begin{array}{l}\text { Kjeldahl } \\
\text { (NT) }\end{array}$ & $\begin{array}{c}\text { Proteína } \\
\text { verdadeira }\end{array}$ & $\begin{array}{c}\text { Por } \\
\text { diferença }\end{array}$ & HPLC & \\
\hline 1 & 2,59 & 2,54 & 3,15 & 2,93 & 5,00 & 4,89 & 11,41 \\
\hline 2 & 3,31 & 3,32 & 3,26 & 3,06 & 4,92 & 4,79 & 12,22 \\
\hline 3 & 3,66 & 3,64 & 3,09 & 2,86 & 4,72 & 4,69 & 12,18 \\
\hline 4 & 3,86 & 3,83 & 3,11 & 2,92 & 4,95 & 4,85 & 12,62 \\
\hline 5 & 3,99 & 3,92 & 3,24 & 3,05 & 4,73 & 4,64 & 12,61 \\
\hline 6 & 4,96 & 4,91 & 3,92 & 3,75 & 4,96 & 4,76 & 14,51 \\
\hline 7 & 3,46 & 3,45 & 3,43 & 3,24 & 4,82 & 4,75 & 12,42 \\
\hline 8 & 3,63 & 3,62 & 3,35 & 3,12 & 5,00 & 4,89 & 12,69 \\
\hline 9 & 3,85 & 3,84 & 3,31 & 3,13 & 4,84 & 4,81 & 12,71 \\
\hline 10 & 4,11 & 4,12 & 3,30 & 3,10 & 4,87 & 4,75 & 13,01 \\
\hline 11 & 4,40 & 4,40 & 3,28 & 3,06 & 4,85 & 4,80 & 13,25 \\
\hline 12 & 5,90 & 5,85 & 3,84 & 3,69 & 4,98 & 4,74 & 15,40 \\
\hline
\end{tabular}

$\mathrm{NT}=$ nitrogênio total; HPLC $=$ cromatografia líquida de alta performance

${ }^{a}$ Proteína verdadeira é calculada pela diferença entre o nitrogênio total e o nitrogênio não protéico.

Tabela 2. Composição físico-química das amostras-padrão canadense usadas na calibração do equipamento Bentley 2000 de acordo com os laudos fornecidos pelo laboratório Dairy Herd Analysis System (DHAS)

\begin{tabular}{lcccc}
\hline Amostra & $\begin{array}{c}\text { Teor de gordura } \\
(\mathrm{g} / 100 \mathrm{~g})\end{array}$ & $\begin{array}{c}\text { Teor de proteína } \\
(\mathrm{g} / 100 \mathrm{~g})\end{array}$ & $\begin{array}{c}\text { Teor de lactose } \\
(\mathrm{g} / 100 \mathrm{~g})\end{array}$ & $\begin{array}{c}\text { Sólidos totais } \\
(\mathrm{g} / 100 \mathrm{~g})\end{array}$ \\
\hline 1 & 3,61 & 3,30 & 4,45 & 12,22 \\
2 & 0,04 & 2,43 & 4,71 & 7,96 \\
3 & 3,77 & 3,69 & 4,41 & 12,77 \\
4 & 0,92 & 3,25 & 4,58 & 9,62 \\
5 & 5,22 & 3,54 & 4,36 & 14,00 \\
6 & 3,31 & 3,50 & 4,44 & 12,13 \\
7 & 2,43 & 3,71 & 4,50 & 11,53 \\
8 & 4,28 & 3,09 & 4,41 & 12,65 \\
9 & 2,85 & 2,89 & 4,53 & 11,09 \\
10 & 4,79 & 3,31 & 4,38 & 13,36 \\
11 & 1,88 & 3,47 & 4,52 & 10,76 \\
12 & 5,76 & 3,94 & 4,31 & 14,93 \\
\hline
\end{tabular}

Tabela 3. Média, desvio-padrão e valores mínimo e máximo dos componentes do leite segundo a origem

\begin{tabular}{lcccc}
\hline $\begin{array}{l}\text { Componente } \\
\text { do leite }\end{array}$ & Origem & $\begin{array}{c}\text { Média } \pm \mathrm{DP} * \\
(\mathrm{~g} / 100 \mathrm{~g})\end{array}$ & $\begin{array}{c}\text { Mínimo } \\
(\mathrm{g} / 100 \mathrm{~g})\end{array}$ & $\begin{array}{c}\text { Máximo } \\
(\mathrm{g} / 100 \mathrm{~g})\end{array}$ \\
\hline Gordura & Padrão EUA & $4,02 \pm 0,62$ & 2,63 & 5,32 \\
& Padrão Canadá & $3,74 \pm 0,95$ & 0,36 & 5,65 \\
Proteína & Padrão EUA & $3,36 \pm 0,30$ & 2,64 & 3,91 \\
& Padrão Canadá & $3,22 \pm 0,33$ & 2,49 & 3,92 \\
Lactose & Padrão EUA & $4,67 \pm 0,21$ & 4,05 & 5,02 \\
& Padrão Canadá & $4,49 \pm 0,30$ & 3,55 & 4,89 \\
\multirow{2}{*}{ Sólidos totais } & Padrão EUA & $12,71 \pm 0,97$ & 10,14 & 14,38 \\
& Padrão Canadá & $12,21 \pm 1,19$ & 8,46 & 14,00
\end{tabular}

$\overline{\mathrm{DP}}=$ desvio-padrão. * Média de 12 amostras. 


\section{Silveira et al.}

Tabela 4. Média, desvio-padrão e valores mínimo e máximo dos componentes do leite de amostras individuais de acordo com o método de análise

\begin{tabular}{lcccc}
\hline $\begin{array}{l}\text { Componente } \\
\text { do leite }\end{array}$ & Método & $\begin{array}{c}\text { Média } \pm \mathrm{DP} \\
(\mathrm{g} / 100 \mathrm{~g})\end{array}$ & $\begin{array}{c}\text { Mínimo } \\
(\mathrm{g} / 100 \mathrm{~g})\end{array}$ & $\begin{array}{c}\text { Máximo } \\
(\mathrm{g} / 100 \mathrm{~g})\end{array}$ \\
\hline \multirow{2}{*}{ Gordura } & Método de referência & $3,83 \pm 0,89$ & 0,44 & 5,51 \\
& Método IV & $3,84 \pm 0,91$ & 0,36 & 5,65 \\
Proteína & Método de referência & $3,29 \pm 0,34$ & 2,51 & 3,92 \\
& Método IV & $3,28 \pm 0,35$ & 2,49 & 3,91 \\
Lactose & Método de referência & $4,58 \pm 0,27$ & 3,75 & 4,97 \\
& Método IV & $4,51 \pm 0,32$ & 3,55 & 5,02 \\
\multirow{2}{*}{ Sólidos totais } & Método de referência & $12,39 \pm 1,18$ & 8,61 & 14,32 \\
& Método IV & $12,38 \pm 1,22$ & 8,46 & 14,38 \\
\hline
\end{tabular}

$\mathrm{IV}=$ infravermelho; $\mathrm{DP}=$ desvio-padrão.

Não houve diferença entre os métodos de análise $(\mathrm{P}>0,05)$.

Tabela 5. Média, desvio-padrão e valores mínimo e máximo dos componentes do leite resfriado de conjunto de acordo com o método de análise

\begin{tabular}{lcccc}
\hline $\begin{array}{l}\text { Componentes } \\
\text { do leite }\end{array}$ & Análise/ Método & $\begin{array}{c}\text { Média } \pm \mathrm{DP} \\
(\mathrm{g} / 100 \mathrm{~g})\end{array}$ & $\begin{array}{c}\text { Mínimo } \\
(\mathrm{g} / 100 \mathrm{~g})\end{array}$ & $\begin{array}{c}\text { Máximo } \\
(\mathrm{g} / 100 \mathrm{~g})\end{array}$ \\
\hline Gordura & Método de referência & $3,92 \pm 0,11$ & 3,77 & 4,05 \\
& Método IV* & $3,96 \pm 0,09$ & 3,83 & 4,07 \\
Proteína & Método de referência & $3,25 \pm 0,06$ & 3,20 & 3,36 \\
& Método IV & $3,25 \pm 0,05$ & 3,21 & 3,34 \\
Lactose & Método de referência & $4,72 \pm 0,08$ & 4,58 & 4,81 \\
& $\quad$ Método IV & $4,65 \pm 0,13$ & 4,42 & 4,73 \\
\multirow{2}{*}{ Sólidos totais } & Método de referência & $12,58 \pm 0,12$ & 12,39 & 12,67 \\
& $\quad$ Método IV & $12,56 \pm 0,08$ & 12,45 & 12,63 \\
\hline
\end{tabular}

IV= infravermelho; DP = desvio-padrão.

Não houve diferença significativa entre os métodos de análise $(\mathrm{P}>0,05)$.

\section{CONCLUSÕES}

Os resultados obtidos na análise eletrônica não foram diferentes daqueles feitos por métodos de referência, assim, a análise eletrônica pode ser utilizada com segurança na avaliação da composição do leite bovino. As amostras-padrão de origem americana e canadense apresentaram composição adequada para a calibração dos equipamentos de infravermelho.

\section{AGRADECIMENTOS}

Ao Laboratório de Referência Animal/LARA, Pedro Leopoldo/MG e à Associação Paranaense de Criadores de Bovinos da Raça Holandesa, Curitiba/PR.

\section{REFERÊNCIAS BIBLIOGRÁFICAS}

AULDIST, M.J.; WALSH, B.J. e THOMSON, N.A. Seasonal and lactational influences on bovine milk composition in New Zealand. $J$. Dairy Res., v.65, p.401-411, 1998.

BARBANO, D.M.; CLARK, J.L. Symposium: Instrumental methods for measuring components of milk- Infrared milk analysis - challenges for the future. J. Dairy Sci., v.72, p.1627-1636, 1989.

BENTLEY Instruments, Inc. Bentley 2000. Operator`s manual. Minesota, 1994.

BIGGS, D.A.; JOHNSSON, G.; SJAUNJA, L.O. Analysis of fat, protein, lactose and total solids by infra-red absorption. In: Monograph on rapid indirect methods for measurement of the major 
components of milk. Bull. Int. Dairy Fed., n.208, p.21-29, 1987.

BRASIL. Instrução Normativa $n^{\circ} 51$ de 20 set. 2002. Ministério da Agricultura, Pecuária e Abastecimento

BRITO, J.R.F.; SOUZA, G,N.; BRITO, M.A.V.P. et al. Panorama da qualidade do leite na Região Sudeste: Espírito Santo, Minas Gerais e Rio de Janeiro. In: BRITO, J.R.F.; PORTUGAL, J.A.B. Diagnóstico da qualidade do leite, impacto para a indústria e a questão dos resíduos de antibióticos. Juiz de Fora: Embrapa Gado de Leite, 2003. Cap.5, p.47-61

DÜRR, J.V.Panorama da qualidade do leite na Região Sul: Rio Grande do Sul. In: BRITO, J.R.F.; PORTUGAL, J.A.B. Diagnóstico da qualidade do leite, impacto para a indústria e a questão dos resíduos de antibióticos. Juiz de Fora: Embrapa Gado de Leite, 2003. Cap.1, p.918.

GOFF, H.D.; HILL, A.R. Chemistry and Physics. In: HUY, Y.H. Dairy science and technology handbook. New York: VCH, 1993. V.1, p.1-82.

GUILLOU, H.; PELISSIER, J.P.; GRAPPIN, R. Méthods de dosage des proteins du lait de vache. Lait, v.66, p.143-175, 1976.

HARVEY, J. A high performance liquid chromatography method for lactose determination in milk. Austr. J. Dairy Technol., v.43, p.19-20, 1988.

INTERNATIONAL Dairy Federation. Standards 1 C. Milk. Determination of fat content. Brussels: IDF, 1987.
INTERNATIONAL Dairy Federation. Standards 141 B. Whole milk - Determination of milk fat, protein and lactose content. Guide for the operation of mid-infrared instruments. Brussels: IDF, 1996.

INTERNATIONAL Dairy Federation. Standards 20 B. Milk. Determination of nitrogen content. Brussels: IDF, 1993.

INTERNATIONAL Dairy Federation. Standards 21 B C. Milk. Determination of total solids content. Brussels: IDF, 1987.

INTERNATIONAL Dairy Federation. Standards 50 C. Guidance on sampling. Brussels: IDF, 1995.

JENSEN, R.G. Invited review: The composition of bovine milk lipids: January 1995 a December 2000. J. Dairy Sci., v.85, p.295-350, 2002.

NICKERSON, S.C. Milk production: Factors affecting milk composition. In: HARDING, F. Milk quality. London: Blackie Academic \& Professional, 1995. Cap.2, p.3-23.

PICININ, L.C.A. Qualidade do leite e da água de algumas propriedades leiteiras de Minas Gerais. 2003. 89 f. Dissertação (Mestrado em Medicina Veterinária) - Escola de Veterinária , Universidade Federal de Minas Gerais, Belo Horizonte.

SPSS. SPSS Base 7.0 For Windows User's Guide. Chicago:SPSS, 1996. 564 p.

SWAISGOOD, H.E. Chemistry of the caseins. In: FOX, P.F. Advanced dairy chemistryproteins. England: Elsevier Science Publishers Ltd, 1992. V.1, p.63-110. 